\title{
Turn-On Eco-Quotient, A Step to Sustainable Fashion
}

\section{Mohana Priya R}

Lecturer, Apparel Training \& Design Centre, Bangalore.

\section{Paper History:}

Received : March. 2020

Accepted : April 2020

Published : May 2020

Corresponding Author:

Mohana Priya R

mohanapriyaa_r@rediffmail.com

\begin{abstract}
The textile and fashion industry are a huge industry with the multiple sectors which use multifold resources to meet the needs of the customers. The fast fashion has ended up with more environment threats. The sustainable fashion is the solution to minimize the ecological impacts and reduce the resources and wastes. It focuses on how the product can stay during its entire life cycle with less impact to the environment. It is big challenge to be sustainable textile and fashion sector because of non-vertical business model.
\end{abstract}

Keywords: Ecological, sustainable, Self-assessment tool, Upcycle

Citation: Mohana Priya R, Turn-On Eco-Quotient, A Step to Sustainable Fashion, Research Journal of Textile and Leather, 1(1), 36-39, 2020.

\section{INTRODUCTION}

Textile and apparel industry are the largest industry having the longest supply chain and generating more employment. The rise in population and increase in demand have made the textile and apparel industry to work as fast as possible. This concept of feeding the mass market at faster rate is called as "Fast Fashion". The growth has made considerable impact on environment and the whole supply chain is responsible for various kinds of pollution like land, water, air and noise. The concept of environmentalism has now changed to sustainability which needs complete revolution involving the experts and innovative eco-thinkers starting from fibers to customer. All the layers of industry should get transformed and become more creative to become sustainable. We have to minimize wastages and maximum utilization of resources and start imparting the concept of Recycle and Upcycle with aim to minimize landfills. Fashion and textile industry have more ecological factors.

The customers are unaware of what they wear and what their contribution towards environmental impact is. More information related to product and the recycle concepts are to be disseminated to make the industry sustain.

\section{FASHION INDUSTRY}

Fashion and apparel industry play major role in environmental impact. The fashion industry contributes $10 \%$ of global emissions and the utilization of garments have gone high because it is a status quotient. The customers prefer more clothing choices. Australia stands the second largest for new apparel consumers whereas US bags its first position. The survey says that global fashion and textile landfill is $6000 \mathrm{~kg} / 10$ minute. The revolution of online retailing is increasing the consumption pattern and will result in increase in the use of transportation which in turn lead to notable rise in carbon footprint. Managing the landfill is the biggest challenge and has to be addressed by the concepts of ethical fashion, Up-cycling and recycling.

The brands have to become and follow-up the supply chain to ensure the sustainable fashion. The leading international brands are now started focusing on sustainable and ethical fashion and want to maintain the transparency by enclosing the facts and figures in all the stages of process. It shows their responsibility 
towards the environment. They wish to source the materials from the supplier who meet the requirements like usage of red listed chemicals, labour, minimum wage power, usage of natural fibres, etc.

The designer has to be critically innovative in developing the fashion which is long lasting and suitable for many occasions with less or no modification. Multi-purpose design facet should be adopted to minimize the frequency of purchase and the design thought process should result in durable design ideas.

\section{ETHICAL FASHION}

The definition of fashion is the most accepted style for a particular time but now the fashion which is accepted considering number of aspects. The main measure of acceptance is its ethical issues. The ethical audit starts from fiber to disposal/recycle and the importance is also given to ensure how the work force is treated in the whole supply chain.

The designers who are innovative with their designs should also become innovative and more creative in developing the designs or materials which are eco-friendly and they have to think of how the designs will reduce frequent purchase and pave the way for upcycling the wardrobe every time.

\section{ECO-LABELLING}

Eco-certification which authenticates that products are environmentally friendly has to be practiced for all textile and fashion products. The eco-labels help market - based changes rather than policies. 'ecolabel is a label which identifies overall environmental preference of a product within a product category based on life cycle consideration' The evaluation should be transparent and each component of supply chain have to be evaluated. The labels should speak on human ecology and product ecology.

They should disseminate the information on lifecycle, reuse and upcycle options also. Though the adoption process is difficult, it will improve the value of the brand as customers are more educated on pollution and adverse effects.

\section{THE FASHION BRANDS AND SUSTAINABILITY}

The fashion industry is having the longest supply chain starting from fiber to customer where all the processes have major environment impact. The leading fashion brands have to become transparent in analyzing the stages and come up with innovative technologies to reduce pollution and make fashion as sustainable one. Natural fibres like cotton cannot be claimed as environment friendly because for their production more water is required and fertilizers and pesticides are used whereas the production of synthetic fibres will end-up in greenhouse effect and increase the carbon foot print.

It's high time for the brands to educate the customers in the selection of products as well as disposal of garments. Every international brand's oath should be reducing over production which will in turn reduce the tones of unsold clothing landfill. The unsold garments landfill has invisible wastage of energy throughout its supply chain. Market intelligence is important because the demand survey will help to produce only what is needed and avoid the wastage. Instead of wasting resources and ending up with difficulty in managing landfills, the brands can think of a strategic approach.

For example, some of the leading fashion brands like Zara, H\&M and Adidas have come up with commitments to use natural fibres. Zara has declared that by 2025 they use only $100 \%$ natural fibres whereas $\mathrm{H} \& \mathrm{M}$ pledged to uses hundred percentage natural and sustainable materials by 2030. The brand, Adidas have announced to phase out virgin polyester by 2024 . These initiations taken by them will pave the path for sustainable fashion. They should be very cautious in reducing the over production and landfills.

Some international brands have introduced the attractive offers to customers to encourage the recycle concepts. They collect the old clothes and give promotional offers in the purchase of new clothe bus. The collected garments are categorized, recycled and used for making home textile products like carpets. The lowcost production techniques compromise the ecological factors and hence the government regulation can become more focused on ensuring the sustainable sourcing, production as well as consumption and disposal. 


\section{TOOLS FOR SUSTAINABILITY}

The research has been taking place in reducing ecological issues. Some tools are developed and introduced to manufacturers which will guide them to assess the environmental impact of their products throughout the supply chain. In this paper we discuss about two of them which are focusing the complete supply chain.

\subsection{HIGG Index}

The Higg Index is self-assessment tool used to evaluate the environmental standards of an apparel and footwear industry. It is the tool to assess social sustainability. The Higg Index 1.0 is based on life-cycle thinking and span of the apparel life cycle. It was introduced by the Sustainable Apparel Coalition (SAC), a nonprofit organization found by a group of fashion companies, the United States government Environmental Protection Agency and other non-profit entities.

Higg index is structured in three modules to evaluate environmental standards taking into account of life-cycle of the product. Higg Index 1.0 focuses on practical questions and is qualitative which insists on improvement of environmental policies of the organization.

The Higg Index is an indicator-based tool designed to evaluate each stages of manufacturing from the raw material to retail and promote continuous improvement to sustainability. Higg Index measures the performance of the organization to meet the environmental standards

\subsection{Fashion Transparency Index}

The Fashion Transparency Index is a tool which helps to review the policies followed by the brands with regard to social and environmental. It answers the questions asked by the customers about the supply chain, labour involved and their welfare, grievances answered, work culture, waste management, principles of recycle, future goals and their impact on sustainability, etc. This tool ranks the brands based on the transparency data they disclose.

This will help customers to understand the complete supply chain and vulnerability to environment as well as various measures taken by the brands to face the challenges to transform as sustainable manufacture from the fibre to finished product including recycling concepts. It ensures the accountability of each person in the supply chain. Textile and fashion have a very long supply chain including various industries from various sectors leading to difficulty in implementing any policies and assess the same.

FTI 2019 was released by 200 international leading brands, with 5\% increase in the transparency comparing to 2018 and the brands are ranked according to the information that they shared related to their supply chain policies and how they manage social and environmental impact. The highest FTI score is $64 \%$ and the highest scoring brands are Adidas, Reebok and Patagonia. This FTI shows, there is always the room for improvement.

No major brands score above $70 \%$. Although, last year in 2018, no brands scored above $60 \%$ and no brands above 50\% in 2017. At the highest score of $64 \%$ this year.

The scores are not based on the performance with reference to sustainable fashion but based on how much information they disclose publicly about their human rights and environmental policies, practices and impacts. Knowing the complete information about the complete chain of the product, it is easy to hold the industry to account for the claims.

\subsection{EU Eco-label}

The EU Eco-label for textiles is label which is analyzing the ecological criteria of the product. It awards the European Community Eco-label to textile products based on the critical evaluation. It is designed to encourage the products which are eco-friendly to enter the market. This also facilitates the customer to become eco-conscious and become a contributor to save the planet.

\section{CONCLUSION}

It is being witnessed that unforeseen depletion of natural resources, unmanageable pollution of all-natural resources, environmental or climatic crisis. The planet of life is now transforming as planet of threat with lot ecological changes and human health issues. Though it will take long way to make a paradigm change and transform to sustainable production, business and consumption, it is very important to focus on concrete, critically innovative and implementable ideas to reduce the waste and pollution. 


\section{REFERENCES}

[1]. Briceno, T., Stagl, S. (2006). The Role of Social Processes for Sustainable Consumption. Journal of Cleaner Production, 14(17) 1541-1551. doi: 10.1016/j.jclepro.2006.01.027

[2]. Law, K.M., Zhang, Z.M., Leung, C.S. (2004). Fashion Change and Fashion Consumption: The Chaotic Perspective. Journal of Fashion Marketing and Management, 8(4) 362-374.

URI: http://hdl.handle.net/10397/20058

[3]. Whitmarsh, L., O'Neill, S. (2010). Green Identity, Green Living? The Role of Proenvironmental Self-identity in Determining Consistency across Diverse Pro-environmental Behaviors. Journal of Environmental Psychology, 30(3) 305314. doi:10.1016/j.jenvp.2010.01.003

[4]. Friedman, T.L. (2008). Hot, Flat, and Crowded: Why Need a Green Revolutionand How it Can Renew America, Waterville, Maine, Thorndike Press.

[5]. Black, S. (2008), Eco-chic: The Fashion Paradox. Black Dog Publishing, London. Web: http://www.apparelcoalition.org 